\title{
Obtención y caracterización de aislados proteicos de colza
}

\author{
Por N. Gonçalves', J. Vioque, A. Clemente, R. Sánchez-Vioque, J. Bautista² y F. Millán \\ Departamento de Fisiología y Tecnología de Productos Vegetales. Instituto de la Grasa, \\ C.S.I.C. Apdo. 1078, 41012 - Sevilla, España. \\ 1. L'école Nationale des Ingenieurs des Techniques des Industries Agricoles et Alimentaires (ENITIAA), \\ Nantes, Francia. \\ 2. Departamento de Bioquímica, Bromatología y Toxicología. Facultad de Farmacia, \\ Universidad de Sevilla, España.
}

\section{RESUMEN} colza.

Obtención y caracterización de aislados proteicos de

Se ha diseñado un proceso de obtención de aislados proteicos a partir de harina de colza desengrasada. El método incluye la extracción básica de las proteínas solubles seguido de una precipitación ácida en el punto isoeléctrico. El precipitado es lavado con agua ( $\mathrm{pH}$ 4.5), etanol y acetona, obteniéndose un aislado proteico con un $86 \%$ de proteína y reduciéndose el contenido en polifenoles y azúcares solubles en más de un $90 \%$ respecto a la harina desengrasada. El aislado final presenta unas características físico-químicas que lo hacen atractivo para su uso en alimentación y obtención de hidrolizados proteicos.

PALABRAS-CLAVE: Aislado proteico - Características físicoquímicas - Colza.

\section{SUMMARY}

Obtention and characterization of rapeseed protein isolates.

A method for the obtention of protein isolates from defatted rapeseed flour has been designed. The process includes a basic extraction followed by a precipitation at the isoelectric point of the proteins. The precipitate is washed with water $(\mathrm{pH} \mathrm{4.5),} \mathrm{ethanol} \mathrm{and}$ acetone, obtaining a protein isolate with $86 \%$ of protein and reducing the contents in polyphenols and soluble sugars in more than $90 \%$ with respect to the defatted flour. The final product have physico-chemical characteristics that make it atractive to be used as food and for the obtention of protein hydrolizates.

KEY-WORDS: Physico-chemical characteristics - Protein isolate - Rapeseed.

\section{INTRODUCCIÓN}

En España y particularmente en Andalucía se produce una gran cantidad de residuos agroindustriales ricos en proteínas, del orden del millón de Tm/año (Boletín de Información Agraria y Pesquera, 1996).
La presencia de compuestos indeseables o antinutricionales junto con las proteínas en dichos subproductos, hacen que este tipo de residuo no se aproveche de forma adecuada. Estos residuos representan una de las reservas con mayor potencial de aplicación para la industria alimentaria, industria de las fermentaciones (como fuente de nitrógeno), producción de piensos compuestos, etc. Para ello es preciso desarrollar procesos adecuados que potencien la calidad de las proteínas constituyentes.

La colza (Brassica oleracea L.) es una fuente importante de grasa vegetal en el mundo, ocupando el cuarto lugar tras la soja, algodón y girasol. En España, la producción de colza ha ido en aumento en los últimos años, alcanzando las $100.000 \mathrm{Ha}$ cultivadas en 1995, de las cuales el 50\% están localizadas en Andalucía (Anuario de Estadística Agraria, 1996). La finalidad principal de su cultivo es la obtención del aceite. Como subproducto de la extracción del aceite se obtiene un residuo que, genéricamente, recibe el nombre de torta. Este residuo desengrasado tiene un contenido proteico que puede oscilar entre el $34 \%$ y el $50 \%$, siendo equilibrado respecto a su composición aminoacídica. Así pues, la harina de colza desengrasada (HCD) presenta un alto contenido en proteínas que la hacen interesante para su utilización en la elaboración de aislados proteicos (Tzeng et al., 1990; Simbaya et al., 1995).

En los últimos años se están intentando desarrollar un gran número de procesos de hidrólisis de proteínas a escala comercial (Parrado et al., 1993a; Parrado et al., 1993b; Bautista et al., 1996). La utilización racional de la HCD como residuo para la producción de hidrolizados proteicos exige la extracción previa de su fracción proteica siendo necesario optimizar la obtención del aislado proteico a partir de la harina desengrasada. Este tipo de hidrolizados proteicos constituyen una aplicación potencial para este tipo de aislados.

En este trabajo se describe un sistema de obtención de aislados proteicos de colza como paso previo para el inicio de la obtención de hidrolizados proteicos y se discuten las características físico-químicas de la harina y de los aislados proteicos obtenidos. 


\section{PARTE EXPERIMENTAL}

\subsection{Material}

Como materia prima se utilizó harina de colza desengrasada industrialmente, con bajo contenido en ácido erúcico y glucosinolatos, suministrada por la empresa Koipesol Semillas. Proteasa, $\alpha$-amilasa y amiloglucosidasa fueron proporcionadas por Sigma (St Louis, MO, U.S.A.).

\subsection{Determinación de humedad, cenizas y grasas}

Se determinaron de acuerdo con los métodos estándar de la A.O.A.C. (1980).

\subsection{Determinación de contenido en fibras}

El contenido en fibra total se determinó mediante el método enzimático-gravimétrico (Lee et al., 1992). Las muestras $(1 \mathrm{~g})$ se homogeneizaron en $40 \mathrm{ml}$ de Mes $50 \mathrm{mM}$, Tris $50 \mathrm{mM}$, pH 8.2 y sucesivamente se digerieron con $50 \mu \mathrm{l}$ de una solución de $\alpha$-amilasa termoestable $\left(15 \mathrm{~min}\right.$ a $\left.95^{\circ} \mathrm{C}\right), 100 \mu \mathrm{l}$ de una solución de proteasa, $50 \mathrm{mg} / \mathrm{ml}\left(30 \mathrm{~min}\right.$ a $\left.60^{\circ} \mathrm{C}\right)$ y $300 \mu \mathrm{l}$ de una solución de amiloglucosidasa ( $30 \mathrm{~min}$ a $60^{\circ} \mathrm{C}$ ). Tras la digestión, las muestras se filtraron por filtros con tamaño de poro de 40-60 $\mu \mathrm{m}$ y el residuo insoluble se pesó y secó determinándose el contenido proteico y de cenizas. El porcentaje en fibra total se calculó con la siguiente fórmula:

Fibra total $(\%)=$ residuo insoluble $(\mathrm{g})$ - proteína (g) - cenizas (g)]/muestra (g) $\times 100$.

\subsection{Determinación de lípidos libres}

Para la extracción de los lípidos libres, la harina o el aislado se extrajo con hexano durante seis horas a temperatura ambiente con una relación harina:disolvente 1:10 (p:v).

\subsection{Determinación de lípidos asociados}

Los lípidos asociados se extrajeron siguiendo el método de Nash et al. (1967). Para ello, el aislado proteico fue extraído con etanol del $86 \%$ en proporción 1:25 (p:v) a T ambiente durante 36 horas.

\subsection{Determinación de azúcares solubles}

La cantidad de azúcares solubles fue determinada mediante el método de Dubois et al. (1956). Para ello, $5 \mathrm{~g}$ de la harina desengrasada fueron extraídos con $200 \mathrm{ml}$ de etanol del 95\% mediante agitación durante dos horas a temperatura ambiente. Tras centrifugar a
$4000 \times \mathrm{g}$ durante $15 \mathrm{~min}$, el sobrenadante fue filtrado

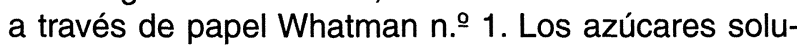
bles se estimaron colorimétricamente usando una curva estándar de glucosa.

\subsection{Determinación de polifenoles}

Se realizó a partir de un extracto etanólico obtenido de forma similar al utilizado para la determinación de los azúcares solubles. El volumen de etanol se redujo a $25 \mathrm{ml}$ mediante concentración en vacío. La muestra se filtró por papel Whatman n.ำ 1, utilizándose alícuotas para medir la absorbancia a $324 \mathrm{~nm}$. La cantidad de compuestos fenólicos se determinó como equivalentes de ácido clorogénico (Moores et al., 1948).

\subsection{Determinación de sólidos disueltos}

Los sólidos disueltos se determinaron por gravimetría llevando a sequedad un extracto etanólico del $95 \%$.

\subsection{Absorción del agua}

Se determinó de acuerdo con Sosulski (1962). Para ello las muestras $(3 \mathrm{~g})$ se mezclaron con $25 \mathrm{ml}$ de agua y se agitaron 6 veces durante $1 \mathrm{~min}$ a intervalos de $10 \mathrm{~min}$. La mezcla se centrifugó a 1000xg durante $25 \mathrm{~min}$, el sobrenadante se desechó y el residuo se calentó en un horno a $50^{\circ} \mathrm{C}$ durante 25 min para eliminar el resto del agua no absorbida. A continuación el residuo se pesó y la absorción de agua se expresó como gramos de agua absorbida por 100 gramos de muestra.

\subsection{Absorción de aceite}

Se siguió el método de Lin et al. (1974). Para ello, muestras de $0.5 \mathrm{~g}$ se mezclaron con $6 \mathrm{ml}$ de aceite de colza y se dejaron en reposo durante $30 \mathrm{~min}$. La mezcla se centrifugó a $1600 x g$ durante 25 min y se midió el volumen del sobrenadante. Los resultados se expresaron como gramos de grasa absorbida por $100 \mathrm{~g}$ de muestra.

\subsection{Contenido en nitrógeno no proteico}

La determinación del nitrógeno no proteico se realizó mediante el método de Bhatty et al. (1973). Para ello la harina fue extraída con etanol del $70 \%$ en una proporción 1:40 (p:v). Se agitó durante una hora a temperatura ambiente y se centrifugó a $4000 x g$ durante 10 min. En el sobrenadante se determinó el contenido en nitrógeno por el método de Kjeldahl (AOAC 1975). 


\subsection{Contenido en nitrógeno proteico}

La determinación de nitrógeno total se realizó según el método de Kjeldahl (AOAC 1975). El contenido en nitrógeno proteico se obtuvo por la diferencia con el no proteico. Se utilizó el factor 6.25 para obtener las cantidades proteicas correspondientes.

\subsection{Digestibilidad proteica in vitro}

Se evaluó de acuerdo al método de Hsu et al. (1997). Las soluciones proteicas $(6.25 \mathrm{mg} / \mathrm{ml}$ en agua destilada) se ajustaron a $\mathrm{pH} 8$ con $\mathrm{NaOH} 0.1 \mathrm{~N}$ agitándose durante dos horas a $37^{\circ} \mathrm{C}$ en un baño. La mezcla de proteasas (1.6 mg tripsina, $3.1 \mathrm{mg}$ quimiotripsina y $1.3 \mathrm{mg}$ peptidasa $/ \mathrm{ml}$ ) se mantuvo en hielo y se ajustó también a pH 8 con $0.1 \mathrm{~N} \mathrm{NaOH}$. La solución de enzimas se añadió a la de proteínas en una relación 1:10 (v:v), registrándose la disminución de $\mathrm{pH}$ tras un período de $10 \mathrm{~min}$. El porcentaje de digestibilidad proteica $(Y)$ se calculó a partir de la ecuación $Y=210.47$ 18.1X, donde $\mathrm{X}$ representa el valor de $\mathrm{pH}$ tras $10 \mathrm{~min}$ (Hsu et al., 1977).

\subsection{Análisis de aminoácidos}

Las muestras (10 mg) se hidrolizaron con $4 \mathrm{ml}$ de $\mathrm{HCl} 6 \mathrm{~N}$. Las soluciones se incubaron en atmósfera de nitrógeno durante $24 \mathrm{~h}$ a $100^{\circ} \mathrm{C}$. Los aminoácidos se determinaron mediante hidrólisis ácida, tras derivatización con dietil etoximetilenemalonato, mediante HPLC de acuerdo con el método de Alaiz et al. (1992), usando el ácido $D, L-\alpha$-aminobutírico como estándar interno. Las pérdidas de aminoácidos sensibles a la hidrólisis ácida se consideraron para una cuantificación precisa. El equipo de HPLC consistió en un multisistema Model 600E con un detector 484 UV-Vis (Waters, Milford, MA). La separación se realizó con una columna de fase reversa $300 \times 3.9 \mathrm{~mm}$ I.D. (Novapack $C_{18}, 4 \mu$, Waters) utilizando un sistema de gradiente binario. Los solventes usados fueron (A) $25 \mathrm{mM}$ acetato de sodio con $0.02 \%$ azida sódica $(\mathrm{pH} 6)$ y $(\mathrm{B})$ acetonitrilo. Los solventes se inyectaron en la columna con un flujo de $0.9 \mathrm{ml} / \mathrm{min}$ de la siguiente forma: tiempo $0-3$, min, gradiente linear de $A: B(91: 9)$ a $A: B$ (86:14); 3-13 min, elución con $A: B(86: 14) ; 13-30$ min gradiente linear de $A: B(86: 14)$ a $A: B(69: 31) ; 30-35$ min, elución con $A: B(69: 31)$. La columna se mantuvo a $18^{\circ} \mathrm{C}$ con un controlador de temperatura (Julabo F10).

\subsection{Determinación del punto isoeléctrico}

La harina desengrasada de colza se extrajo tres veces con $\mathrm{NaOH} 0.2 \%$ en una relación 1:10 (p:v). Los extractos se centrifugaron a $4000 \mathrm{xg}$ durante $20 \mathrm{~min}$. Se reunieron los sobrenadantes y se determinó el nitrógeno total. A continuación se tomaron alícuotas que se llevaron a diferentes $\mathrm{pHs}$ desde 2.5 hasta 6.5 a intervalos de 0.5 unidades de $\mathrm{pH}$. Se centrifugaron estas alícuotas a 4000xg durante $20 \mathrm{~min}$. y se recuperaron los sobrenadantes en los que se determinó el nitrógeno. Con estos valores, referidos al extracto alcalino de partida, se determinó el punto isoeléctrico.

\section{RESULTADOS Y DISCUSIÓN}

\subsection{Obtención del aislado proteico}

En la figura 1 se muestra el sistema de obtención de aislado de proteínas de colza. La HCD recibe primero un pretratamiento con el objeto de reducir los contenidos de compuestos no deseables en el producto final tales como fibras, azúcares reductores, polifenoles, sales o lípidos. Dicho tratamiento consiste en cuatro lavados con agua, seguido de un proceso de flotación-sedimentación. A continuación se realizan dos lavados con etanol al $20 \%$, para disminuir los contenidos en polifenoles.

El concentrado proteico así obtenido es extraído en medio básico usando $\mathrm{NaOH}$ al $0.2 \% \circ \mathrm{OH}_{2} \mathrm{SO}_{3}$ al $0.25 \%$. Con estas soluciones se extraen aproximadamente el $60 \%$ de las proteínas (Tabla I). En general, el rendimiento obtenido con los distintos sistemas probados es inferior al obtenido con otros productos, que ronda el $75 \%$. Probablemente, el tratamiento previo para la extracción del aceite desnaturaliza parcialmente las proteínas, provocando un descenso de su solubilidad debido a la aparición en la superficie de grupos hidrófobos y a la agregación de moléculas desplegadas.

Cuando se extraen las proteínas con $\mathrm{NaOH}$ en una relación 1:10, el rendimiento de la primera extracción es menor que usando la relación 1:20, debido probablemente a su alta viscosidad.

Aunque el rendimiento del proceso es menor con $\mathrm{H}_{2} \mathrm{SO}_{3}$ mejora el proceso de extracción desde un punto de vista de la calidad del aislado obtenido, impidiendo la formación de puentes disulfuro. Además, éste se oxida en lugar de los polifenoles previniendo la formación de quinonas y el oscurecimiento del aislado proteico.

A continuación, las proteínas solubles así extraídas se precipitan llevando la solución al punto isoeléctrico de éstas $(\mathrm{pH} 5)$. El rendimiento de esta precipitación se aproxima al $60 \%$ debido a que la colza presenta proteínas con un amplio rango de $\mathrm{pl}$, obteniéndose a pH 5 una cantidad elevada de compuestos proteicos en solución.

El precipitado obtenido es lavado sucesivamente con agua, etanol y acetona para eliminar los restos de compuestos solubles no proteicos que pudieran quedar en el mismo, obteniéndose un aislado de proteínas que es filtrado y secado, pudiendo ser utilizado directamente en la producción de hidrolizados proteicos. 


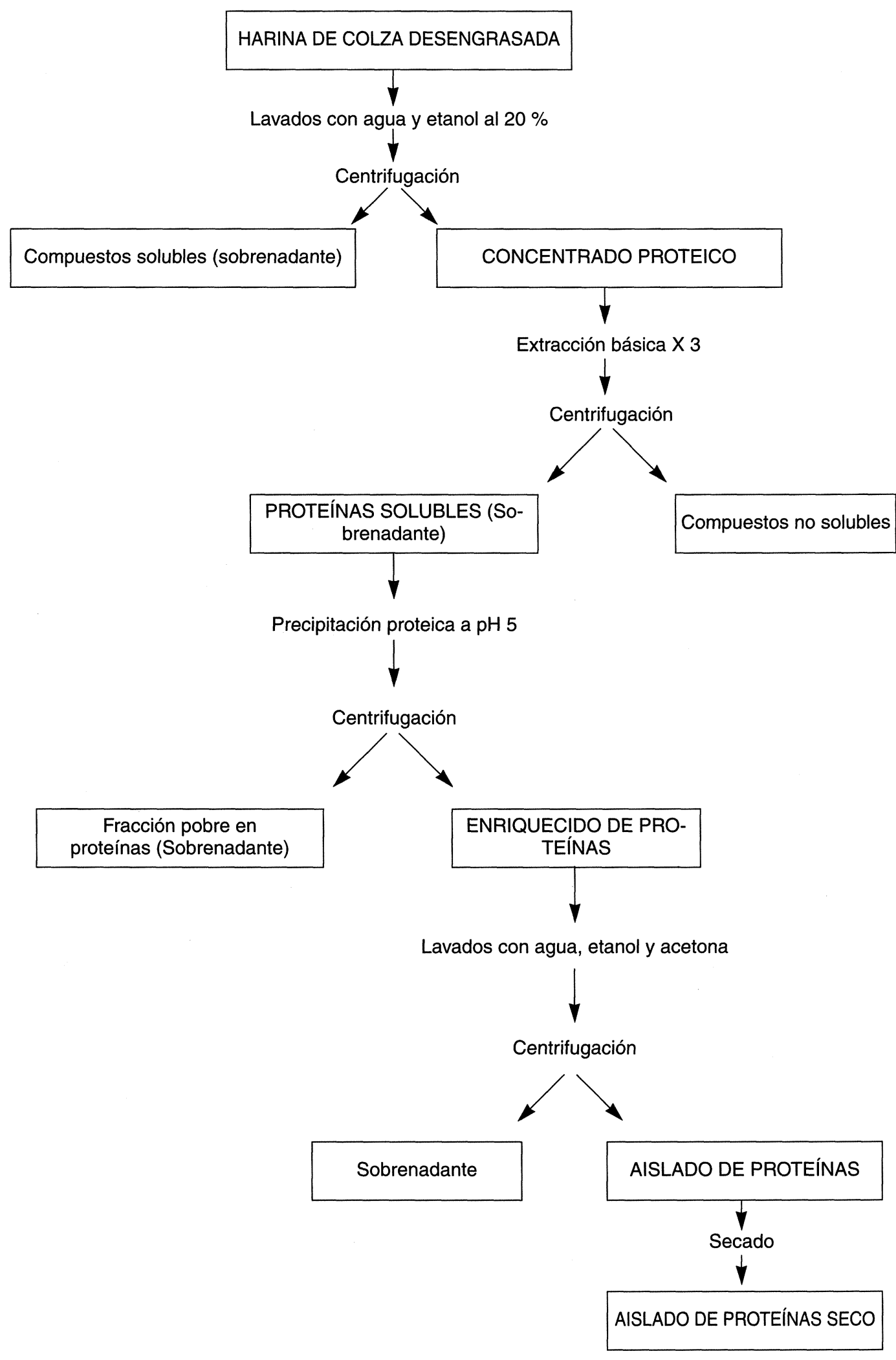

Figura 1

Proceso de obtención de un aislado proteico de colza 
Tabla I

Extracción de las proteínas de la colza

\begin{tabular}{lccc}
\hline Extracciones & $\mathbf{0 . 2 \%} \mathbf{~ N a O H , ~ p H ~ 1 2}$ & $\mathbf{0 . 2} \% \mathbf{~ N a O H , ~} \mathbf{p H ~ 1 2}$ & $\mathbf{0 . 2 5 \%} \mathbf{~ S O}_{\mathbf{3}} \mathbf{H}_{\mathbf{2}}, \mathbf{p H ~ 1 0 . 5}$ \\
\hline Relación harina: líquido & & & $1: 10$ \\
de extracción (p:v) & $1: 10$ & $1: 20$ & 41.8 \\
Primera & 34.7 & 45.0 & 7.2 \\
Segunda & 18.0 & 10.9 & 1.6 \\
Tercera & 7.1 & 3.0 & 50.6 \\
Total & 59.8 & 58.9 & \\
\hline
\end{tabular}

Los valores se expresan en \% referidos al material original.

Cada valor representa la media \pm desviación estándar de tres medidas.

\subsection{Caracterización físico-química de la harina de colza y del aislado proteico}

En la tabla II se muestran las características generales de la HCD así como de los aislados proteicos lavados con agua o con agua, etanol y acetona.

El componente mayoritario de la HCD son las proteínas (31.4\%) seguidas de las fibras (29.5\%). Así mismo, los sólidos disueltos (13\%) y los azúcares solubles $(4.9 \%)$ se encuentran en cantidades significativas. La concentración de lípidos es muy baja ya que han sido extraídos previamente. La presencia de compuestos no deseables en el aislado proteico como son las fibras, azúcares solubles, polifenoles o sólidos disueltos, que pueden reaccionar con las proteínas, disminuyendo la calidad de las mismas, hacen deseable su eliminación para el aprovechamiento adecuado de las proteínas.

La humedad de la harina usada es del $4.4 \%$. Este valor permite almacenar la harina hasta su uso sin riesgo de que sufra alteraciones químicas o de que crezcan microorganismos.

El contenido en fibras (celulosa, hemicelulosa y lignina) es alto en relación a otras oleaginosas. Esto se debe al tamaño pequeño de la semilla respecto a la cáscara, rica en fibras. En el proceso de extracción del aceite no se elimina la cáscara ya que el germen está unido a ella. La eliminación de las fibras tiene dos aspectos positivos, permite ampliar el espectro de utilización de la HCD a animales no rumiantes y reduce los fenómenos de absorción inespecífica de las proteasas sobre la fibra, optimizándose el proceso hidrolítico.

Con el método de obtención de aislados proteicos descrito se reducen los lípidos libres a valores indetectables y los lípidos asociados en más de un $50 \%$. Los lípidos presentes en el aislado proteico pueden interaccionar con las proteínas produciendo olores rancios así como sabores amargos o astringentes. Así mismo, pueden incrementar la retencion de los compuestos resultantes de la propia oxidación lipídica, reduciendo el valor nutricional de las proteínas.
Con el método descrito, los contenidos en azúcares se reducen en más de un $90 \%$ en el aislado proteico final. Los azúcares constituyen otra fracción cuya eliminación es positiva, ya que pueden interaccionar con las proteínas mediante la reacción de Maillard produciendo bases de Shiff. Estas bases derivan a compuestos como cetosaminas o aldosaminas disminuyendo la biodisponibilidad de estos aminoacidos esenciales. Además, los azúcares disminuyen las posibilidades de utilización de las proteínas al caramelizar a alta temperatura. También, desde un punto de vista dietético, es interesante limitar su ingestión.

Los sólidos disueltos están representados principalmente por aldehidos, cetonas, alcoholes y fenoles que, al reaccionar con las proteínas, producen olores indeseables. Los contenidos en sólidos disueltos se reducen en más de un $95 \%$ en el caso del aislado lavado con agua, etanol y acetona.

Los contenidos en polifenoles se han reducido también en más de un $90 \%$ en los aislados obtenidos. La eliminación de los polifenoles es deseable ya que, en presencia de oxígeno, pueden oxidarse a las quinonas correspondientes que pueden reaccionar con residuos aminoacídicos produciendo un aislado proteico de color parduzco.

La absorción de agua y aceite son importantes características funcionales que afectan a la calidad del alimento. La primera mejora la textura del alimento, aunque altos niveles de absorción de agua no tienen por qué ser positivos, ya que un material con una alta absorción puede embeber una desproporcionada cantidad de agua y deshidratar otros componentes del sistema. Los valores inferiores observados en los aislados proteicos son debidos a la disminución en compuestos más higroscópicos, como los azúcares. Los valores obtenidos para esta variedad de colza son beneficiosos y se encuentran dentro del rango determinado para otras variedades (Mansour et al., 1992; Xu et al., 1994). 
Tabla II

Características de la harina desengrasada y de los aislados proteicos de colza

\begin{tabular}{lccc}
\hline & Harina original & $\begin{array}{c}\text { Aislado proteico } \\
\text { lavado con agua }\end{array}$ & $\begin{array}{c}\text { Aislado proteico } \\
\text { lavado con agua } \\
\text { acetona y alcohol }\end{array}$ \\
\hline Humedad & 4.4 & 2.1 & 11.7 \\
Cenizas & 7.0 & - & - \\
Fibras & 29.5 & - & - \\
Riqueza grasa & 1.3 & 0 & 0 \\
Lípidos libres & 0.83 & - & 1 \\
Lípidos asociados & 2.2 & 0.3 & 0.3 \\
Azúcares solubles & 4.9 & 0.2 & 0.05 \\
Sólidos disueltos & 13.0 & 0.14 & 0.05 \\
Polifenoles & 2.0 & 253.5 & 207.4 \\
Absorción de agua & 352.7 & 284.1 & 128.7 \\
Absorción de grasa & 149.8 & - & 86.0 \\
Riqueza no proteica & 31.4 & - & - \\
Nitrógeno no proteico & 0.57 & - & 91.6 \\
Digestibilidad & 84.2 & Negro & Gris claro \\
Color & & & \\
\hline
\end{tabular}

Los valores se expresan en $\%$ referidos al material original.

La absorción de aceite es tambien un parámetro positivo, ya que la grasa absorbida protege frente a la desnaturalización térmica. Los aminoácidos hidrófobos van a ser los principales puntos de interacción entre lípidos y proteínas. Los valores detectados para esta variedad entran dentro del rango observado para los aislados de colza (Mansour et al., 1992; Xu et al., 1994).

El punto isoeléctrico es ácido, centrado alrededor de pH 5 (figura 2). Este valor es similar al observado en otras variedades de colza (Mahajan et al., 1995).

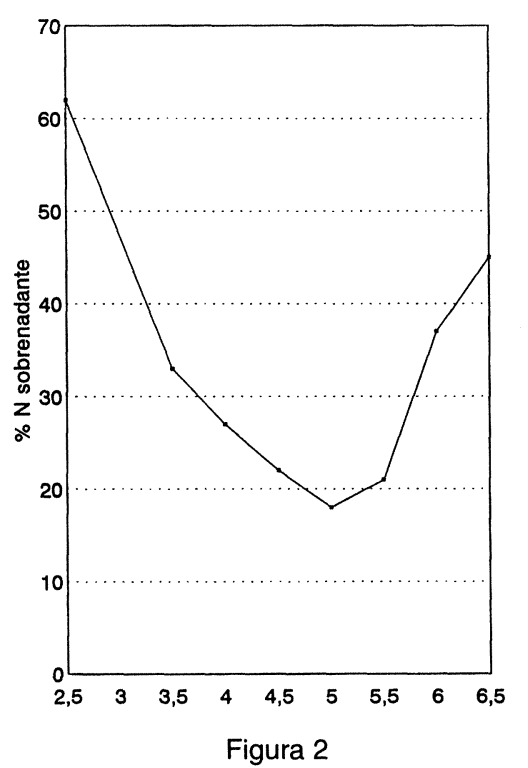

Punto isoeléctrico de las proteínas de colza
Por último, los valores obtenidos para la digestibilidad in vitro son bastante altos, sobrepasando el $90 \%$ en el aislado lavado con agua, alcohol y acetona.

\subsection{Composición aminoacídica}

Se ha determinado la composición en aminoácidos de la harina de colza (tabla III). Los contenidos en fenilalanina, tirosina y lisina están por debajo de las recomendaciones de la FAO (1985), aunque los valores en aminoácidos azufrados sí cumplen los requisitos de la FAO. Así pues, si la HCD es utilizada como materia prima para la obtención de aislados, deben tenerse en cuenta estas deficiencias aminoacídicas y su corrección, por ejemplo, suplementando la HCD con otros alimentos no deficitarios en estos aminoácidos o con aporte artificial de los mismos. Así mismo, sería de interés intentar incrementar las cantidades de estos aminoácidos limitantes en la colza, bien por mejora genética clásica o mediante técnicas de biología molecular, por ejemplo, incrementando la expresión de proteínas más ricas en los aminoácidos deficitarios.

\subsection{Clasificación de las proteínas de colza}

Las proteínas constituyentes del extracto proteico se clasificaron de acuerdo al método de Osborne et al. (1897) (tabla IV). Así, las proteínas más abundantes son las solubles en agua o albúminas con un $49.4 \%$ seguidas de las globulinas, proteínas solubles en $\mathrm{NaCl} 1 \mathrm{M}$, 
Tabla III

Composición de aminoácidos

\begin{tabular}{|c|c|c|c|}
\hline & $\mathrm{g} / 100 \mathrm{~g}$ de aa & g/ $100 \mathrm{~g}$ de proteínas & $\begin{array}{r}\text { g/ } 100 \mathrm{~g} \text { de proteínas } \\
\text { FAO (1985) }\end{array}$ \\
\hline Aspártico & 9.3 & 8.3 & \\
\hline Glutámico & 18.5 & 18.3 & \\
\hline Serina & 6.8 & 4.8 & \\
\hline Histidina & 2.6 & 2.7 & \\
\hline Glicina & 10.5 & 5.3 & \\
\hline Treonina & 5.4 & 4.4 & 3.4 \\
\hline Arginina & 6.4 & 7.5 & \\
\hline Alanina & 6.5 & 3.9 & \\
\hline Prolina & 5.3 & 4.1 & \\
\hline Tirosina & 2.1 & 2.6 & \\
\hline Valina & 4.3 & 3.4 & 3.5 \\
\hline Metionina & 2.3 & 2.3 & $2.5^{\mathrm{a}}$ \\
\hline Cistina & 1.4 & 2.3 & \\
\hline Isoleucina & 3.2 & 2.8 & 2.8 \\
\hline Leucina & 7.3 & 6.4 & 6.6 \\
\hline Fenilalanina & 3.2 & 3.5 & $6.3^{\mathrm{b}}$ \\
\hline Lisina & 4.9 & 4.8 & 5.8 \\
\hline
\end{tabular}

Cada valor representa la media \pm desviación estándar de tres medidas.

${ }^{\mathrm{a}}$ Metionina + cisteína. ${ }^{\mathrm{b}}$ Tirosina + fenilalanina.

que representan un $31.6 \%$. En menor cantidad se encuentran las prolaminas, extraídas con alcohol al $70 \%$, y las glutelinas extraídas con $\mathrm{NaOH}$ a $\mathrm{pH} 11$.

Tabla IV

Clasificación de Osborne de las proteínas de colza

\begin{tabular}{lc}
\hline Proteína & Contenido \\
\hline Albúminas & 49.4 \\
Globulinas & 31.6 \\
Prolaminas & 0.4 \\
Glutelinas & 18.6 \\
\hline
\end{tabular}

Los valores se expresan en \% referidos al material original. Cada valor representa la media \pm desviación estándar de tres medidas

\section{CONCLUSIONES}

Se ha puesto a punto un sistema de obtención de aislados proteicos a partir de harina de colza desengrasada que consiste en una extracción de las proteínas solubles a pH básico y una precipitación posterior de las mismas al pl ácido. Con el método diseñado se reducen en más de un $90 \%$ los contenidos en sustancias indeseables para el aislado proteico, como azúcares, fenoles y otros en relación a la harina original.

El aislado proteico final tiene una riqueza en proteínas del $86 \%$, una digestibilidad in vitro del $91.6 \%$ y unos valores de absorción de agua y aceite que proporcionan un producto deseable para su uso en alimentación, pudiendo utilizarse como materia prima para la obtención de hidrolizados proteicos.

Este método puede hacerse extensible a otros materiales procedentes de la extracción del aceite con 
un contenido elevado de proteínas de buena calidad, tales como la harina de girasol desengrasada o semillas de leguminosas no utilizadas para consumo directo.

\section{AGRADECIMIENTOS}

Este trabajo ha sido financiado en parte por el proyecto de investigación ALI 95-0734 del Plan Nacional de Ciencia y Tecnología de Alimentos.

\section{BIBLIOGRAFÍA}

Alaiz, M., Navarro, J., Girón, J. y Vioque, E. (1992). -«Amino acid analysis by high performance liquid chromatography after derivatization with diethylethoxymethylenemalonate»- Journal Chromatography 591, 181-186.

Anuario de Estadística Agraria (1996).- Ed. Servicio Técnico del Ministerio de Agricultura, Pesca y Alimentación.

AOAC (1975). - «Association of Official Analytical Chemist. Official Methods of Analysis, 12 edn., "- Washington DC.

Bautista, J., Hernández-Pinzón, I., Alaiz, M., Parrado, J. y Millán, F. (1996). -«Low molecular weight sunflower protein hydrolysate with a low concentration in aromatic amino acids"- Journal of Agricultural and Food Chemistry 44, 967-971.

Bhatty, R. (1973). - «Extraction of nonprotein nitrogen from oil seed meal with different solvents»-Cereal Chemistry $\mathbf{5 0}$, 329-336.

Boletín de Información Agraria y Pesquera (1996). -Ed. Junta de Andalucía. Consejería de Agricultura y Pesca.

Dubois, M., Gilles, K., Hamilton, J., Rebers, P. y Smith, F. (1956). - «Colorimetric method for determination of sugars and related substances"- Analytical Chemistry 28, 350-356

FAO/WHO/ONU (1985) - «Energy and protein requirements. Report of a joint meeting"- WHO, Geneva, technical report series $\mathrm{N} 724$.

Hsu, H., Vavak, D., Satterlee, L. y Miller, G. (1977). -«A multienzyme technique for estimating protein digestibility»- Journal Food Science 42, 1269-1273.

Lee, S., Prosky, L. y De Vries, J. (1992). -«Determination of total, soluble and insoluble dietary fiber in foods enzymatic- gravimetric method, MES-Tris buffer: collaborative study.»- Journal American Office Analytica Chemistry International 75, 395-416.

Lin, M.J., Humbert, E. S., Sosulski, F. W. (1974). - “Certain functional properties of sunflower meal products."Journal Food Science 39, 368-370.

Mahajan, A. y Dua, S. (1995). - «Functional properties of rapeseed protein isolates.- Journal Food Science Technology 32, 162-165.

Mansour, E. H., Peredi, J. y Dworschak, E. (1992). - «Preparation and functional properties of rapeseed protein products»- Acta Alimentaria 21, 293-305.

Moores, R., Mc Dermott, D. y Wood, T. (1948). - "Determination of chlorogenic acid in coffee»Analytical Chemistry 28, 620-624.

Nash, A. M., Eldridge, A. C. y Wolf, W. J. (1967) - -Fractionation and characterization of alcohol extractables associated with soybean proteins. Nonprotein components."- Journal Agriculture Food Chemistry 15, 102-108.

Osborne, T. B. y Campbell, G. T. (1897). - «The proteins of the sunflower seed"- Journal American Chemical Society 19, 487.

Parrado, J., Millán, F., Fernández-Pinzón, I., Bautista, J. y Machado, A. (1993 a) - "Characterization of enzymatic sunflower protein hydrolysates»- Journal of Agricultural and Food Chemistry 41, 1821-1825.

Parrado, J., Millán, F., Hernández-Pinzón, I., Bautista, J. y Machado, A. (1993 b) -«Sunflower peptones: use as nitrogen source for the formulation of fermentation media»- Process Biochemistry 28, 109-113.

Simbaya, J., Slominsky, B. A., Rakow, G., Campbell, L. D., Downey, R. K. y Bell, J. M. (1995). - "Quality characteristics of yellow-seeded Brassica seed meals: protein, carbohydrates, and dietary fiber components"Journal Agriculture Food Chemistry 43, 2062-2066.

Sosulski, F. (1962). - «The centrifuge method for determining flour absorption in hard red spring wheats»- Cereal Chemistry 39, 344-350.

Tzeng, Y. M., Diosaday, L. L. y Rubin, L. J. (1990). - «Production of canola protein materials by alkaline extraction, precipitation, and membrane processing»Journal of Food Science 55, 1147-1156.

Xu, L. y Diosday, L. L. (1994) - «Functional properties of chinese rapeseed protein isolates"- Journal of Food Science 59, 1127-1130.

Recibido: Julio 1997 Aceptado: Septiembre 1997 